И зотретиноин в терапии акне

\author{
М. М. Тлиш, М. Е. Шавилова
}

ФГБОУ ВО «Кубанский государственный медицинский университет» Минздрава России 350063, г. Краснодар, ул. Седина, д. 4

Системные ретиноиды признаны наиболее эффективным средством терапии тяжелых форм акне. Однако, несмотря на длительную и усиленную практику их применения в дерматологии, некоторые специалисты до сих пор избегают назначения данной группы препаратов. Как правило, это связано с недостаточной информированностью врачей о схемах терапии и способах коррекции возможных побочных эфффектов. В статье рассмотрены клинические аспекты назначения изотретиноина в терапии среднетяжелых и тяжелых форм акне, даны практические рекомендации, как предупредить различные мисры, заблуждения и предубеждения со стороны врачей и пациентов. Представлен собственный опыт применения изотретиноина с увеличенной биодоступностью (Акнекутан $\left.{ }^{\circledR}\right)$.

Ключевые слова: акне, системные ретиноиды, изотретиноин, Акнекутан ${ }^{\circledR}$.

Контактная информация: marina@netzkom.ru. Вестник дерматологии и венерологии 2017; (4): 90—96.

\title{
Isotrethinoine in acne therapy
}

\author{
M. M. Tlish, M. E. SHavilova
}

Kuban State Medical University

Sedina str., bldg 4, Krasnodar, 350063, Russia

Systemic retinoids are known to be the most effective means of treating severe forms of acne. However, in spite of longstanding and intensive practice of their application in dermatology, some specialists still avoid prescribing this group of drugs. As a rule, this is due to lack of awareness of health professionals about therapy techniques and means of correcting possible adverse events. We discuss the clinical aspects of administration of isotretinoin in treatment of moderate and severe forms of acne. Practical recommendations are given on how to prevent various myths, misconceptions and prejudices in health professionals and patients. We present our own experience of using isotretinoin with increased bioavailability $\left(\right.$ Acnecutan ${ }^{\circledR *}$ )

Key words: Acne, systemic retinoids, isotretinoin, Acnecutan ${ }^{\circledR}$.

Corresponding author: marina@netzkom.ru. Vestnik Dermatologii i Venerologii 2017; 4: 90—96.

\footnotetext{
* В Бельгии препарат зарегистрирован под торговым названием Isosupra Lidose и производится компанией «SMB Laboratories S. A.».
} 
На разных этапах жизни с проблемой акне сталкиваются 80-95\% населения. Пик заболеваемости приходится на 12-25 лет, при этом высыпания могут сохраняться и в более позднем возрасте, а в $41 \%$ случаев впервые возникнуть после окончания полового созревания. В отличие от многих других дерматозов при acne vulgaris поражается главным образом кожа лица, что отрицательно влияет на психоэмоциональное состояние пациентов [1, 2].

Несмотря на активное изучение причин и механизмов развития вульгарных угрей, лечение заболевания по-прежнему представляет определенные сложности. Выбор метода терапии зависит от клинической фрормы и степени тяжести дерматоза: при легком течении заболевания используются только наружные средства, для терапии средних и тяжелых фрорм показано назначение препаратов системного действия - антибиотиков, гормональных препаратов, синтетических ретиноидов. При этом, согласно последним рекомендациям (European Dermatology Forum, 2016 г.), изотретиноин (ИТ) признан наиболее эфффективным средством терапии тяжелых фрорм [2, 3].

Высокая эффективность ИТ в терапии акне обусловлена его влиянием на основные звенья патогенеза заболевания. Препарат воздействует на ретиноидные рецепторы, что приводит к восстановлению терминальной дифференцировки кератиноцитов и пролиферации эпителия протоков сальных желез. Как правило, через 2-3 нед. после начала терапии наблюдается уменьшение продукции себума и, как следствие, снижение колонизации $P$. acnes. Также ИТ способен ингибировать медиаторы воспаления (лейкотриены), давая, таким образом, выраженный противовоспалительный и иммуномодулирующий эффрект [4, 5].

Несмотря на более чем 30-летний опыт применения ИТ, в настоящее время некоторые дерматологи неоправданно избегают назначения препарата. Анализ литературы и собственный опыт показывают, что такое отношение к терапии акне системным ИТ, как правило, связано с недостаточной или неадекватной информированностью врачей и пациентов. С одной стороны, у клиницистов нет четкого представления о том, в каких случаях показан и противопоказан ИТ, какие обследования необходимы перед его назначением, каких побочных реакций следует ожидать в ходе лечения и как минимизировать риск их развития, возможно ли достижение полной ремиссии акне и с чем может быть связано отсутствие эффекта от терапии. С другой стороны, состояние проблемы усугубляется наличием значительного количества недостоверной информации о препарате в сети Интернет, которая доступна большинству пациентов. Все это порождает массу мифов, заблуждений и предубеждений об эффективности и безопасности терапии ИТ и значительно затрудняет и ограничивает его практическое применение [6, 7].

Вместе с тем игнорирование препаратов ИТ при тяжелых фрормах акне приводит к ошибкам в тактике ведения пациентов: длительной неэффективной терапии топическими препаратами и даже попыткам хирургического лечения (вскрытие и дренирование узлов). В большинстве случаев эти способы либо просто бездейственны, либо приводят к утяжелению течения дерматоза и значительно повышают риск рубцевания (рис. 1).

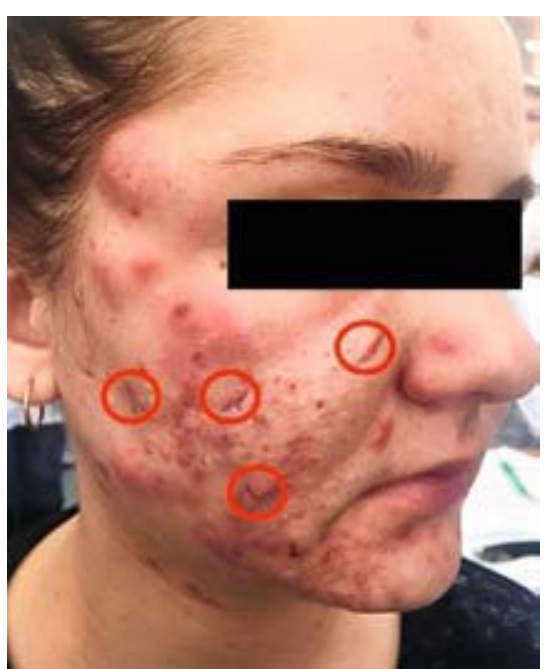

a

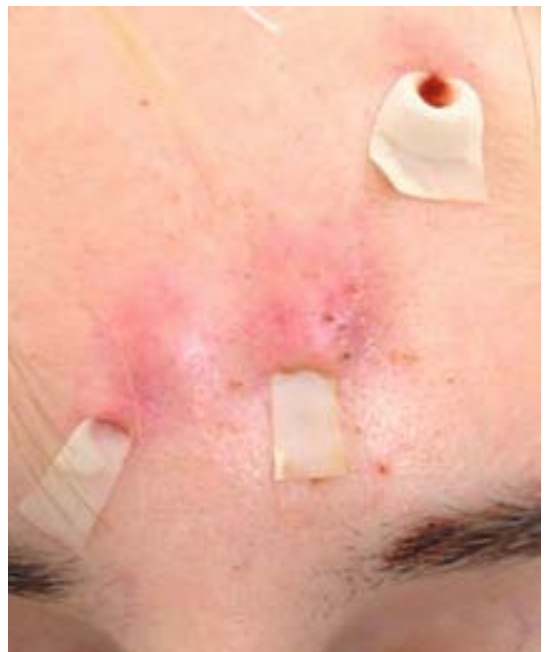

б

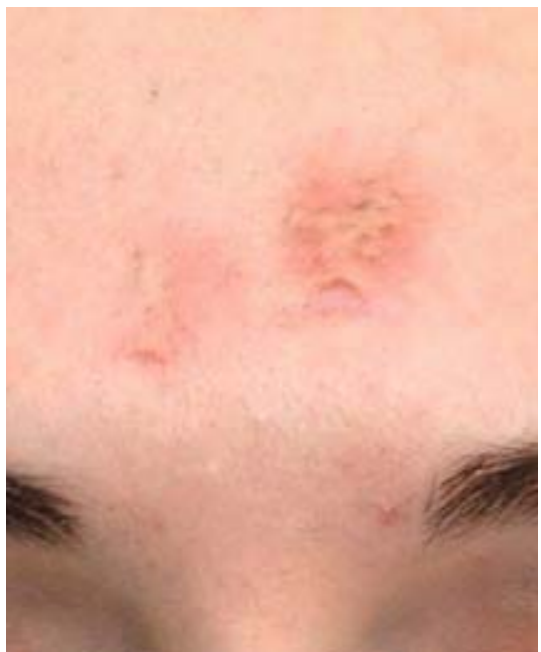

$B$

Рис. 1. Состояние кожи у больных акне после попыток хирургического лечения:

a - выраженные рубцы после вскрытия узлов; б, в - дренирование свищей с формированием грубых рубцов после заживления 


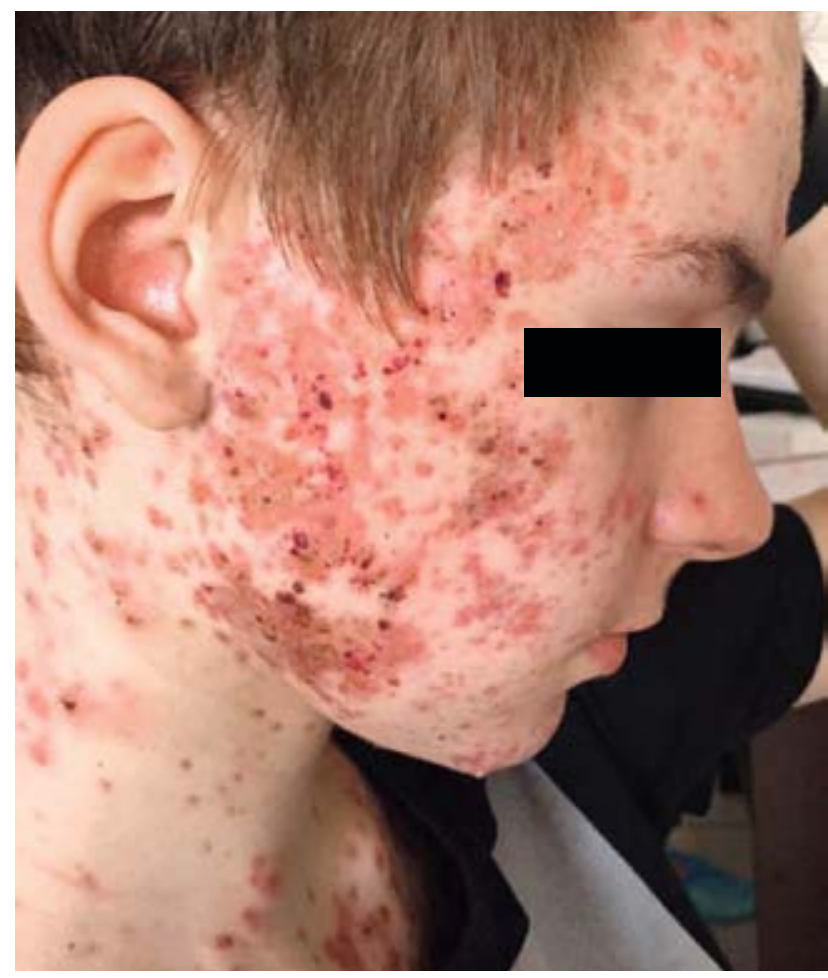

$a$

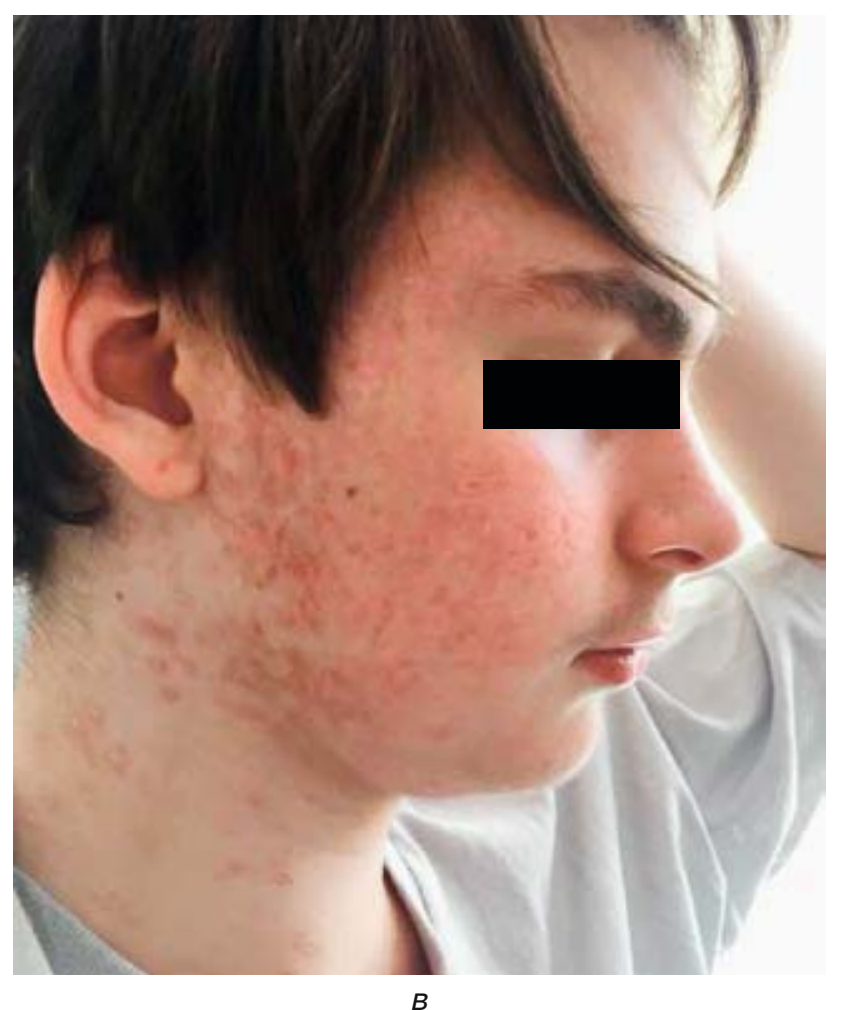

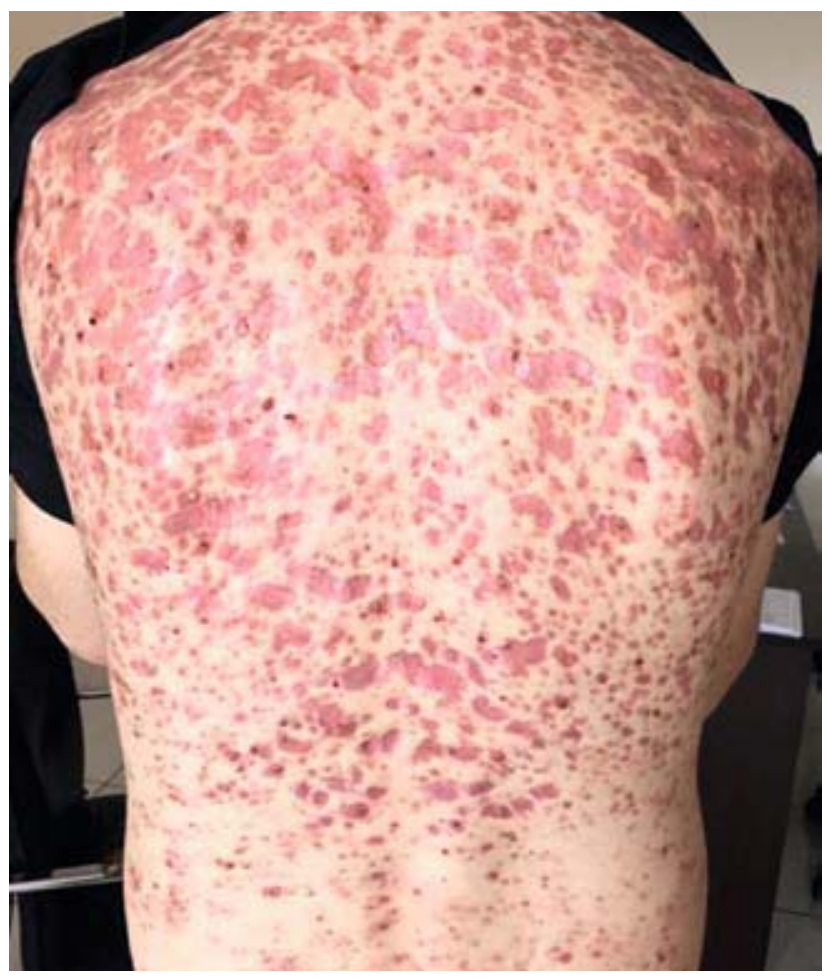

$\sigma$

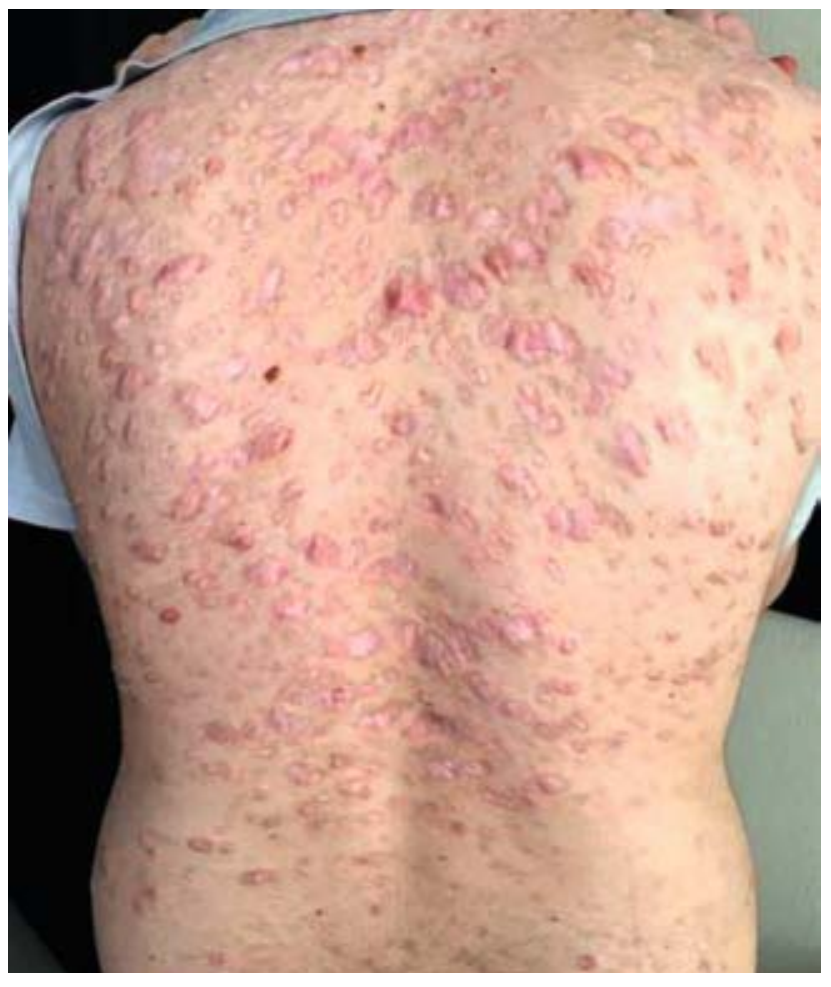

$\Gamma$

Рис. 2. Высыпания на коже лица и спины у больного акне:

a, б - до лечения; в, г — через 9 мес. после начала терапии Акнекутаном ${ }^{\circledR}$, суммарная доза 6480 мг (112 мг/Кг) 
Наиболее частой причиной, из-за которой системная терапия ИТ не назначается, является страх перед риском развития нежелательных эфрфектов на фоне лечения. На данный момент доказано, что все нежелательные реакции ИТ являются дозозависимыми. Вследствие этого особого внимания заслуживает препарат Акнекутан ${ }^{\circledR}$ компании «Ядран» (Хорватия). Используемая при его производстве технология Lidose (SMB Laboratories S.A., Бельгия) позволяет снизить как суточную, так и курсовую дозу ИТ, а следовательно, и риск возникновения побочных реакций в ходе терапии.

Собственный клинический опыт использования данного препарата показывает его высокую эффрективность в лечении среднетяжелых, тяжелых и резистентных к стандартной терапии фрорм акне. Под наблюдением сотрудников кафедры дерматовенерологии ФГБОУ ВО КубГМУ находилось 117 пациентов в возрасте от 12 до 36 лет. У подавляющего числа больных было диагностировано тяжелое (у 41\%) и очень тяжелое (у 30,8\%) течение акне, доля больных со среднетяжелыми фрормами дерматоза составила 28,2\%. В результате проведенной терапии клинической ремиссии достигли 88\% пациентов (рис. 2). У остальных больных отмечено клиническое улучшение, при этом до начала лечения у всех них наблюдались выраженные узловатые или конглобатные формы заболевания.

Несмотря на то что в литературе описано не менее 50 различных возможных осложнений терапии систем- ными ретиноидами, в ходе всего курса лечения серьезных побочных эфрфектов ни у одного больного зарегистрировано не было. Также нами не обнаружены такие нежелательные явления, как выпадение волос, депрессия, тошнота и рвота, боли в эпигастрии. Наиболее часто встречались: хейлит (у всех пациентов), дерматит лица (у 46,1\%), сухость слизистой носа (у 24,8\%) и кожи (у 21,4\%). Реже отмечали: кожный зуд (у 14,5\%), дерматит кистей (у 6\%), сухость конъюнктивы (у 3,4\%), кровоточивость слизистой носа (у 2,6\%) и миалгии (у 1,7\%). При этом сухость кожи, хейлит и дерматит успешно устранялись увлажняющими средствами. С целью профрилактики сухости конъюнктивы глаз пациентам назначали препараты искусственной слезы. Причиной болей в мышцах и суставах, развившихся только у 2 пациентов, было профессиональное занятие спортом. После уменьшения физической нагрузки и коррекции дозы препарата данные симптомы исчезли.

Для минимизации рисков возникновения нежелательных реакций со стороны печени и поджелудочной железы перед началом и в процессе терапии пациентам проводился биохимический анализ крови с обязательным определением трансаминаз и липидов. В нашем исследовании в процессе лечения клинически значимых отклонений от нормы этих показателей выявлено не было: незначительное повышение уровня холестерина зарегистрировано у 7,6\%, активности трансаминаз - у 1,7\% (рис. 3). Данные

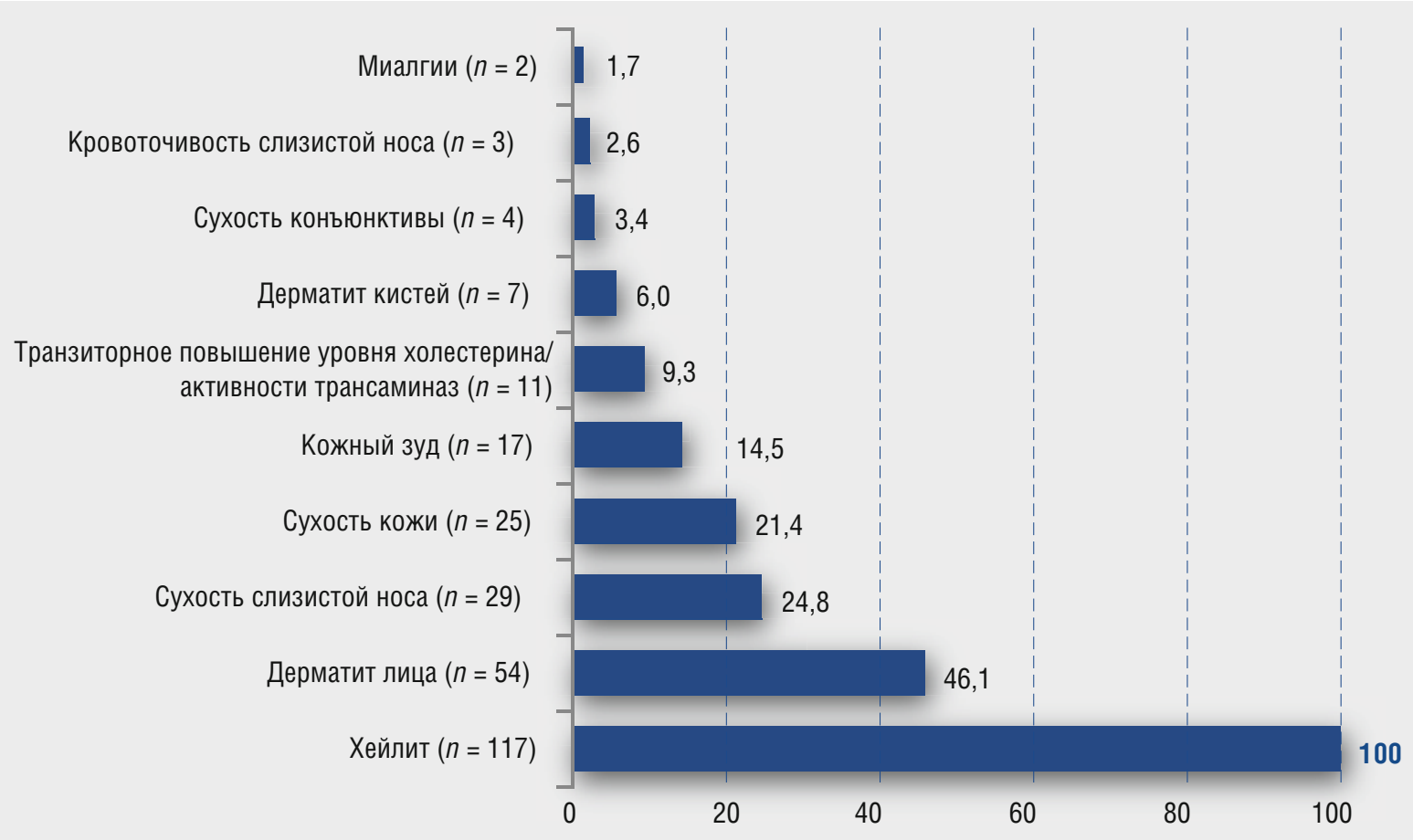

Рис. 3. Частота возникновения и структура нежелательных явлений в ходе терапии Акнекутаном ${ }^{\circledR}(n=117), \%$ 
изменения успешно корректировались назначением диеты с низким содержанием жиров и гепатопротекторов $[8,9]$.

У Акнекутана ${ }^{\circledR}$, как и у любого медицинского препарата, есть свои строгие показания и противопоказания, игнорирование которых может стать причиной развития тяжелых побочных реакций и неэффективности терапии, что в последующем дискредитирует ИТ. Основными показаниями к терапии ИТ при акне являются узловато-кистозные и конглобатные фрормы, а также высокий риск образования рубцов при среднетяжелых и атипичных формах дерматоза и при акне, сочетающихся с выраженными психоэмоциональными расстройствами по поводу заболевания. В то же время использование ИТ при легком течении акне не оправдано с точки зрения соотношения рисков развития побочных явлений и клинической эффективности [2, 3].

Абсолютным противопоказанием к терапии ИТ является беременность. С этим связаны многочисленные мифы о том, что нельзя планировать беременность в течение 6 мес., 1 года, 2 лет или более после окончания лечения ИТ, а также в период, когда препарат принимает супруг пациентки. В обоих случаях ИТ ошибочно приписываются свойства ретиноидов с длительным периодом полувыведения (этретината и ацитретина). При этом в инструкции к Акнекутану ${ }^{\circledR}$ четко прописано, что период полувыведения основного метаболита ИТ составляет 29 ч, а эндогенные концентрации ретиноидов в организме восстанавливаются через 14 дней после последнего приема препарата. Следовательно, планирование беременности можно осуществлять уже через 1 мес. после окончания терапии [2]. Также ИТ не влияет на сперматогенез и при его приеме нет противопоказаний в отношении репродуктивной функции у мужчин. Тем не менее не все врачи это четко понимают и могут аргументированно объяснить пациентам.

Еще одно заблуждение связано с тем, что прием ИТ приводит к образованию рубцов и пигментации. Однако риск появления этих изменений на фоне приема ИТ повышается лишь в случае использования травмирующих косметологических процедур или избыточной инсоляции. Связано это с тем, что одним из механизмов действия синтетических ретиноидов является усиление эпидермопоэза, следствием чего является истончение рогового слоя. Поэтому с целью профилактики дерматита, рубцов и отслойки эпидермиса во время лечения ИТ и в течение 6 мес. после его окончания противопоказаны УФ-облучение, дермоабразия, пилинги, лазерные процедуры и эпиляции. Доказано, что профилактическое использование фотозащитных средств с высоким SPF-фрактором позволяет успешно применять препарат в регионах с жарким климатом. Важно разъяснить пациенту, что правильный и своевременный прием ИТ, наоборот, предотвращает развитие рубцовых изменений и пигментных постакне.

Следует информировать больных о том, что во время терапии ИТ противопоказаны тетрациклины (возможно повышение внутричерепного давления), не рекомендуется назначать оральные контрацептивы с малыми дозами прогестерона (ИТ ослабляет их действие) и препараты, повышающие фоточувствительность (риск солнечных ожогов).

Отсутствие четкого понимания схем дозирования ИТ также часто ограничивает клинический опыт врача в применении препарата при акне. В соответствии с последними рекомендациями по ведению больных акне РОДВК (2016 г.) ИТ назначается из расчета 0,5 мг на 1 кг массы тела в сутки до достижения кумулятивной дозы 120-150 мг/кг. Учитывая технологию Lidose, терапевтическая дозировка Акнекутана ${ }^{\circledR}$ ниже - 0,4-0,8 мг/кг в сутки, курсовая доза - 100120 мг/кг. Суточная доза препарата зависит от его переносимости (количество и выраженность побочных реакций, фототип кожи) и поэтому для каждого пациента подбирается и корректируется в ходе терапии индивидуально. Лечение следует начинать с дозы 0,4 мг/кг 1 раз в сутки. При плохой переносимости терапию можно продолжать в меньшей дозе, но более длительно. Обычно полная ремиссия акне достигается за 16-24 нед., а терапия продолжается до достижения курсовой кумулятивной дозы [2, 8, 9].

Преждевременная отмена ИТ без достижения курсовой дозы нередко может стать причиной рецидива акне, что компрометирует препарат в глазах как специалистов, так и пациентов. Следует понимать, что противорецидивная эффективность ИТ в большой мере связана с его способностью существенно уменьшать размер сальных желез за счет индуцированного апоптоза не только самих себоцитов, но и их стволовых клеток. Так как акне имеет хронический характер течения, это становится возможным только при условии достижения пациентом кумулятивной (курсовой) дозы [2, 3, 10].

Также следует помнить, что резистентность и постоянные рецидивы заболевания в ходе адекватной терапии ИТ в большинстве случаев свидетельствуют о наличии у пациента эндокринных расстройств (синдром поликистозных яичников, гиперплазия гипофиза, вирилизирующие опухоли). Нами была проконсультирована пациентка с тяжелой папуло-пустулезной формой акне, резистентной к традиционным методам терапии, включая терапию ИТ. После сбора анамнеза и осмотра больной было рекомендовано дополнительное обследование у гинеколога и эндокринолога, по результатам которого подтвердился диагноз «микроаденома гипофиза. Пролактинома». Высыпания разрешились только после соответствующего лечения эндокринологического заболевания (рис. 4). 


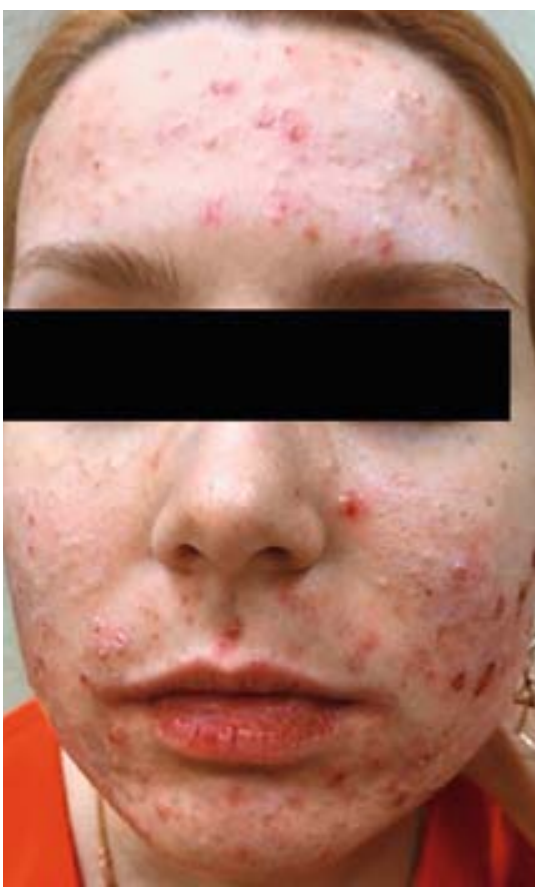

a

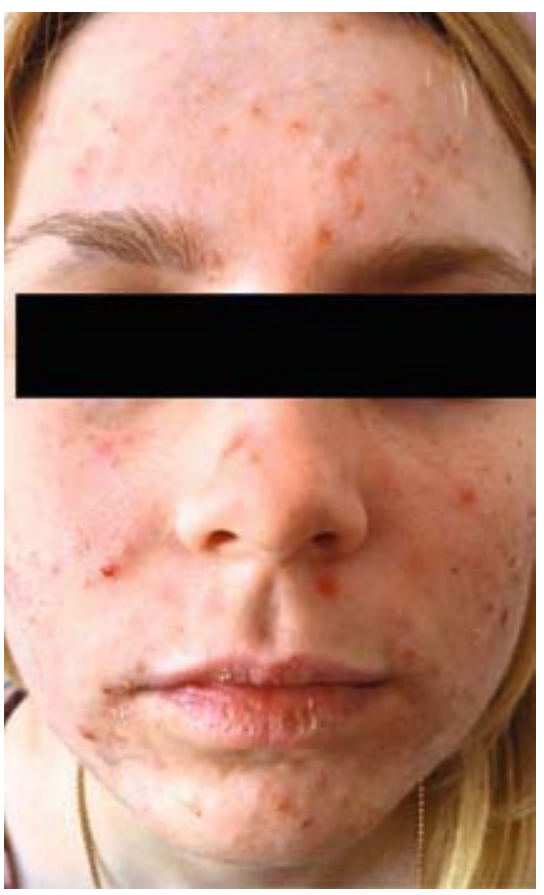

б

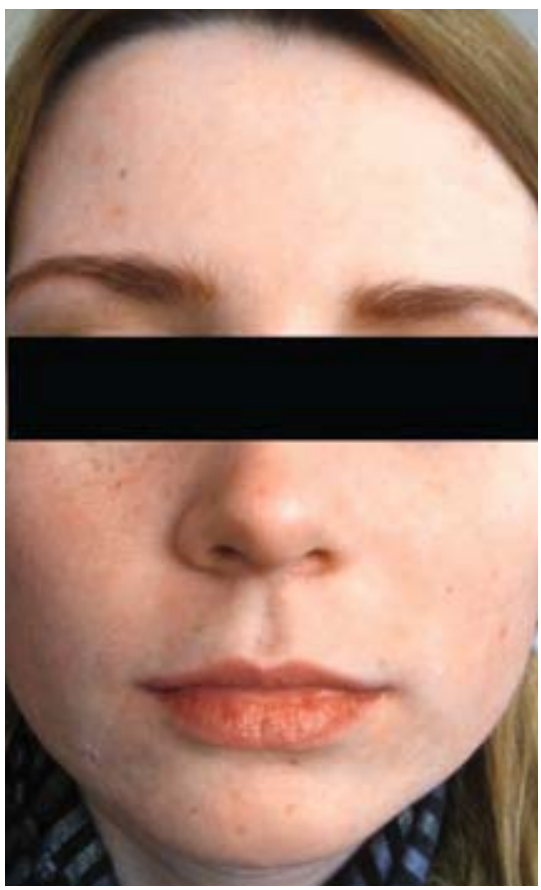

$B$

Рис. 4. Больная акне, развившимися вследствие микроаденомы гипофиза: a - до начала терапии ИТ; $\sigma-6$ мес. терапии ИТ; в - после верификации диагноза и лечения у эндокринолога (бромокриптин)

Таким образом, при правильном назначении Акнекутан $^{\circledR}$ обладает выраженной эфрфективностью и противорецидивной активностью в лечении акне средней и тяжелой степени тяжести. Все нежелательные явления терапии предсказуемы и легко поддаются коррекции, поэтому, несмотря на большое количество заявленных возможных побочных эффектов ИТ, стандартный курс лечения препаратом хорошо переносится и безопасен. Любые неудачи в терапии ИТ следует связывать с неверной или недостаточной диагности- кой основного заболевания, взятием на лечение пациента без учета противопоказаний и предварительного обследования, а также с отсутствием мер профилактики осложнений (эмолентов, адекватной фотопротекции). Следовательно, успех в лечении акне системным ИТ в первую очередь зависит от знаний и опыта дерматолога, что еще раз подтверждает высказывание Парацельса: «Болезни не подстраиваются к теориям врачей. Врач должен понять причину болезни и приспособиться к ней».

\section{Литература}

1. Rocha M.A., Costa C. S., Bagatin E. Acne vulgaris: an inflammatory disease even before the onset of clinical lesions. Inflamm Allergy Drug Targets 2014; 13 (3): 162—7.
2. Kubanova A. A., Kubanov A. A., Samcov A. V., Aravijskaya E. R. Akne. Federal'nye klinicheskie rekomendacii. Dermatovenerologiya: Bolezni kozhi. Infekcii, peredavaemye polovym putem. 5-e izd., pererab. i dop. M.: Delovoj ehkspress, 2016: 9-27. [Кубанова А. А., Кубанов А. А., Самцов А. В., Аравийская Е. Р. Акне. Федеральные клинические рекомендации. Дерматовенерология: Болезни кожи. Инфекции, передаваемые половым путем. 5-е изд., перераб. и доп. М: Деловой экспресс, 2016: 9-27.]
3. Nast A., Dreno B., Bettoli V. et al. European Evidence-based (S3). Guideline for the Treatment of Acne. Update 2016.

4. Harms M. Isotretinoin: 10 years on. Dermatology 1993; 186: 81—82.

5. Ganceviciene R., Zouboulis C. C. Isotretinoin: state of the art treatment for acne vulgaris. J Dtsch Dermatol Ges 2010; 8 (1): S47—59.

6. Rademaker M. Isotretinoin: dose, duration and relapse. What does 30 years of usage tell us? Australas J Dermatol 2013; 54 (3): 157-162. 
7. Kubanova A. A., Araviyskaya Ye.R., Sokolovsky Ye. V., Dvorova Ye.K., Fadeyeva Ye.I. Systematic treatment of strong forms of acne: the use of isotretinoin in the Russian Federation. Vestn dermatol venerol 2013; (5): 102_114. [Кубанова А. А., Аравийская Е.Р., Соколовский Е.В., Дворова Е. К., Фадеева Е.И. Системное лечение тяжелых форм акне: опыт и спользования изотретиноина в Российской Федерации. Вестн дерматол и венерол 2013; (5): 102-114.]
8. Tlish M. M. Experience of treating acne patients with acnecutan. Vestn dermatol venerol 2011; (3): 142-152. [Тлиш М. М. Опыт лечения больных акне препаратом Акнекутан. Вестн дерматол венерол 2011; (3): 142—152.]
9. Tlish M. M., Yelistratova A. S., Gluzmin M.I. Practical aspects of administering Acnecutan for the treatment of acne in teenagers. Vestn dermatol venerol 2013; (4): 85-90. [Тлиш М. М., Елистратова А.С., Глузмин М.И. Практические аспекты применения изотретиноина в лечении акне у подростков. Вестн дерматологи и венерол 2013; (4): 85-90.]

10. Strauss J. S., Stranieri A. M. Changes in longterm sebum production from isotretinoin therapy. J Am Acad Dermatol 1982; 6: 751—6.

об авторах:

М. М. Тлиш — д.м.н., доцент, профессор, зав. кафеедрой дерматовенерологии ФГБОУ ВО КубГМУ Минздрава России, Краснодар

М. Е. Шавилова — ассистент кафеедры дерматовенерологии ФГБОУ ВО КубГМУ Минздрава России, Краснодар

\section{Конфликт интересов}

Авторы заявляют об отсутствии потенциального конфрликта интересов, требующего раскрытия в данной статье 